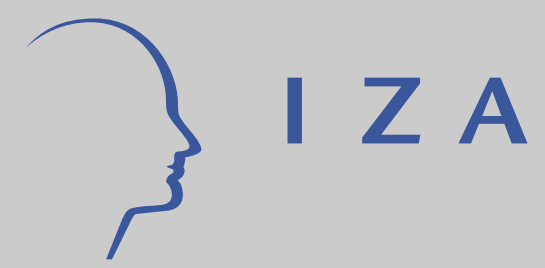

IZA DP No. 5534

Long-term Effects of Famine on Life Expectancy:

A Re-analysis of the Great Finnish Famine of 1866-1868

Gabriele Doblhammer

Gerard J. van den Berg

L.H. Lumey

February 2011

Forschungsinstitut zur Zukunft der Arbeit Institute for the Study of Labor 


\title{
Long-term Effects of Famine on Life Expectancy: A Re-analysis of the Great Finnish Famine of 1866-1868
}

\author{
Gabriele Doblhammer \\ University of Rostock, DZNE Bonn, \\ MPIDR Rostock and RZ Rostock
}

Gerard J. van den Berg

University of Mannheim, IFAU Uppsala, VU University Amsterdam and IZA

L.H. Lumey

Columbia University

Discussion Paper No. 5534

February 2011

IZA

P.O. Box 7240

53072 Bonn

Germany

Phone: +49-228-3894-0

Fax: +49-228-3894-180

E-mail: iza@iza.org

\begin{abstract}
Any opinions expressed here are those of the author(s) and not those of IZA. Research published in this series may include views on policy, but the institute itself takes no institutional policy positions.

The Institute for the Study of Labor (IZA) in Bonn is a local and virtual international research center and a place of communication between science, politics and business. IZA is an independent nonprofit organization supported by Deutsche Post Foundation. The center is associated with the University of Bonn and offers a stimulating research environment through its international network, workshops and conferences, data service, project support, research visits and doctoral program. IZA engages in (i) original and internationally competitive research in all fields of labor economics, (ii) development of policy concepts, and (iii) dissemination of research results and concepts to the interested public.
\end{abstract}

IZA Discussion Papers often represent preliminary work and are circulated to encourage discussion. Citation of such a paper should account for its provisional character. A revised version may be available directly from the author. 


\section{ABSTRACT \\ Long-term Effects of Famine on Life Expectancy: A Re-analysis of the Great Finnish Famine of 1866-1868 ${ }^{*}$}

Famines are extreme cases of environmental stress, and have been used by a series of studies to explore the long-term consequences of the fetal or childhood environment. Results are inconsistent and do not support negative long-term effects on mortality. The authors test the hypothesis that selection during famine changes the frailty distributions of cohorts and may hide negative long-term effects. They use death counts from age 60+ from the Human Mortality Data Base for the birth cohorts 1850-1854, 1855-1859, 1860-1865, 1866-1868, 1869-1874, 1875-1879, 1880-1884 and 1885-1889 to explore the effect of being born during the Great Finnish Famine 1866-1868. Swedish cohorts without famine exposure are analysed as a control group. Cohorts born in Finland during the Great Finnish Famine are highly heterogeneous in their distribution of deaths after age 60. By contrast, cohorts born in the years immediately after the famine are particularly homogeneous. Accounting for these differences results into a lower remaining life expectancy at age 60 for cohorts born during the famine. Statistically, long-term effects of famine on mortality become only visible when changes in the frailty distribution of cohorts are explicitly considered.

JEL Classification: $\quad$ I12, J11, C41

Keywords: $\quad$ old-age mortality, selection, debilitation, early life circumstances

Corresponding author:

Gerard J. van den Berg

University of Mannheim

Department of Economics

L7, 3-5

68131 Mannheim

Germany

E-mail: gerard@uni-mannheim.de

\footnotetext{
" We thank James W. Vaupel for his critical review of the manuscript and his helpful comments. Gerard J. van den Berg is Alexander von Humboldt Professor of Econometrics and Empirical Economics.
} 


\section{INTRODUCTION}

The effects of early life conditions on late-life health and mortality have been repeatedly demonstrated. Historical studies have stressed the adverse long-term consequences of epidemics in childhood diseases ${ }^{1,2}$ or studied the impact of exogenous stressors, such as economic cycles at the time of birth ${ }^{3}$, or the month of birth ${ }^{4,5}$. Meanwhile, research into contemporary populations has focused on the effects of unbalanced nutrition on the human fetus ${ }^{6}$ and the development of the thrifty phenotype $e^{7,8}$. Famines are extreme cases of environmental stress, and have been used by a series of studies to explore the long-term consequences of the fetal or childhood environments. In this context, the most widely studied famines are the Dutch famine of 19441945, the Chinese famine of 1959-1961 and the famine of the Siege of Leningrad in 1944. Various indicators of long-term health have been used and various associations have been found. The available studies show a reproducible association between prenatal famine exposure and adult overweight/obesity, diabetes, and schizophrenia. For other measures of adult health, findings come from single studies or are inconsistent across studies (for a review see').

Conflicting evidence exists concerning the effects of famine on mortality and life expectancy. While an analysis of the Dutch potato famine found higher late-life mortality for cohorts born during the famine ${ }^{10}$, the pioneering national cohort study by Kannisto and colleagues ${ }^{11}$ of the Great Finnish Famine, a study of local births in the Dutch Hunger Winter followed through age 57 years $^{12}$, and the regional study of the Chinese Famine ${ }^{13}$ did not find differences in mortality and survival at older age for cohorts born during famine.

This study re-analyzes the Finnish cohort data used by Kannisto et al. ${ }^{11}$. The initial analysis showed no association between births during the famine and survival beyond age 17. One 
possible explanation for the absence of any long-term effect on survival is that selection during the famine altered the frailty distribution of the population. Selection by famine could operate on each link of the chain from conception to death: conceptions may be reduced and fetal survival, infant survival, as well as survival at older ages affected. We consider three possible selection effects. First, famines generally affect fertility patterns such that the number of births during a famine declines, and rises sharply shortly after the famine $e^{14,15,11}$. The social and biological characteristics of women who conceive and give birth during famines may be different from those of women who have children in normal years. E.g. Stein et al. ${ }^{14}$ showed that the reduction in fertility was greater among manual workers than among those in other occupations. Thus, their offspring may also differ in terms of the factors that influence their long-term health and survival. Second, mortality during famines is not random, resulting in the death of frailer individuals and leaving only the stronger to survive. Therefore, surviving individuals are more homogeneous in terms of frailty ${ }^{16}$.Third, since the surviving population is more homogeneous, the offspring of the survivors should also be more homogeneous. Thus, cohorts born after the famine should display less variability in their levels of frailty.

We model the assumed frailty of a birth cohort by a stochastic distribution. The following predictions result from the ideas presented above: Two forces affect the frailty distribution of the survivors of famines. On the one hand, any negative long-term effect of the famine (debilitation) should make individuals more heterogeneous in their health depending on their biological and social characteristics and their vulnerability to the famine. Therefore, the variance of the frailty distribution should increase. On the other hand, the variance should decrease to the extent mortality will select out the frailer individuals, thus resulting in a more homogeneous group of survivors. These two forces may cancel each other out, resulting in unchanged mortality of cohorts born during the famine. If, however, the debilitation effect is larger than the selection effect, then the variance of the frailty distribution will increase. If the opposite holds and the 
selection effect is larger than the debilitation effect, the variance will decrease. These respective effects will apply to cohorts born before and during the famine in varying degrees, depending on the age-specific vulnerability to famine.

If the debilitating long-term effects of the famine are larger than the mortality selection during the famine, then the frailty distribution of the cohorts born after the famine will have a smaller variance. They are the only cohorts who are not directly affected by the debilitating effects of the famine and should thus have a small variance. In addition they are selected by the fertility of the survivors of the famine which should even further decrease the variance.

If negative long-term consequences of famines exist and the underlying cohort-specific frailty distribution is accounted for, then the cohorts born during the famine should have higher death rates, and may therefore be expected to have lower life expectancy at old age than those born after the famine. The answer to the question of whether they should have higher mortality than cohorts born before the famine is not, however, obvious. It depends on the age that is most vulnerable to famine.

In contrast to the Kannisto et al. ${ }^{11}$ article, which compared birth cohorts between 1861 and 1873 , we explore a longer time period and use cohort data for the birth cohorts 1850 up to 1890 . The reasons are twofold. First, long-term effects of the famine may exist for ages other than the first year of life, and the old-age mortality of all cohorts born before the famine may therefore be altered. Second, because selective fertility may extend well beyond the immediate years of the famine and, the frailty distributions of the cohorts born after the famine may be altered. The Finnish cohort data only exist on a yearly basis and therefore the critical periods during pregnancy or the first year of life cannot be exactly defined. Born after famine for some infants means conceived during famine but not for all in these data. Born during famine could be 
conceived during famine, and/or pregnancy exposed during famine, and/or exposed in infancy during famine.

In addition we control for important period effects, such as the end of World War I/ the Spanish Flu Pandemic in 1918 and World War II which have affected period mortality in Finland. Finally, we compare the mortality of the Finnish and Swedish cohorts born in the 19th century. Unlike Finland, Sweden, which is the country with the best data quality at that period of time, did not suffer from any severe hunger crises in the middle of the 19th century but otherwise is closely comparable to Finland in its mortality regime. Both countries experienced a general mortality decline during the 19th and 20th century, only interrupted by short periodic mortality crises. Similar to other European countries this decline started among the young and shifted towards high ages in the second half of the 20 th century $^{17}$. However, there are also considerable differences: while Sweden has once been among the record holder in life expectancy ${ }^{18}$, Finland was lacking behind in terms of life expectancy, particularly in the 1960s and 1970s (http://www.mortality.org).

\section{MATERIALS AND METHODS}

This study analyzes the death rates of birth cohorts, accounting for unobserved heterogeneity in their distribution of deaths. We distinguish eight cohorts: 1850-1854, 1855-1859, 1860-1865, 1866-1868, 1869-1874, 1875-1879, 1880-1884 and 1885-1889. The birth cohorts 1860-1865 are the immediate pre-famine cohorts, those born between 1866 and 1868 are the famine cohorts, while birth cohorts 1869-1874 are the immediate post-famine cohorts. All analyses are performed separately for males and females. 
For each cohort, the force of mortality $\mu(x)$ over age $\mathrm{x}$ follows a baseline mortality $\mu_{0}$ modified by a frailty distribution $\mathrm{Z}$.

$$
\begin{gathered}
\mu(x)=Z \mu_{0} \\
\mu_{0}=\alpha e^{2 x} e^{\sum_{i=1, \ldots} \beta_{i} Y_{i}}
\end{gathered}
$$

with $\alpha$ and $\gamma$ denoting the parameters of a Gompertz function, and $Y_{i}$ denoting the $n$ indicator variables for the single-year birth cohorts, as well the indicator variables for the period effects of WW I/Spanish Flu and WWII, together, with their parameter estimates $b_{i}$. The frailty distribution Z follows a Gamma distribution with mean one and variance $\sigma^{2}$.

$$
Z \sim \Gamma\left(1, \sigma^{2}\right)
$$

The Gamma distributional assumption is uncontroversial in the study of longevity. Moreover, it can be justified as a limiting frailty distribution among survivors ${ }^{19}$. Notice also that the period dummies $Y_{i}$ act as time-varying explanatory variables on the individual mortality rate. With such variables, the estimation results in survival models are relatively robust with respect to functional form assumptions, like the Gamma and Gompertz assumptions ${ }^{19}$.

In equation (II), $\alpha$ is independent of age and determines the general level of mortality of a cohort. Over cohorts, $\alpha$ is changing, which may counterbalance the cohort trend in the variance of the frailty distribution. An alternative specification is to consider the general level of mortality as part of the frailty distribution, and fix the level of mortality for the various cohorts arbitrarily at the value of one. Thus, equations I to III can be re-written into

$$
\mu(x)=Z \mu_{01}
$$




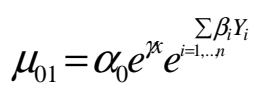

where $\alpha_{0}$ is fixed to one, and

$$
Z \sim \Gamma\left(\alpha, \sigma^{2} \alpha^{2}\right)
$$

The variance $\sigma^{2} \alpha^{2}$, which we name cohort variance, is used to test the three selection hypotheses formulated above, and the hazard rates of the Gompertz function $\mu_{0}$ are used to estimate remaining life expectancy at age 60 for the standard individual of a cohort. For the sake of brevity, we refer to the latter as the standardized life expectancy. We use the natural logarithm of the cohort variance $\ln \left(\sigma^{2} \alpha^{2}\right)$ as the measure of cohort heterogeneity and name it log cohort variance.

The human mortality database http://www.mortality.org contains deaths by Lexis triangles, cross-classified by year of birth, year of death and age ${ }^{20}$. Because we are interested in the longterm effects of famine, we start our mortality analysis at age 60. To avoid the influence of extreme longevity on the variance of the frailty distribution, we right-censor all deaths at age 95 . Since migration at age $60+$ is negligible and all cohorts are extinct, we use the death counts in the Lexis triangles to estimate the age-specific force of mortality for single-year age intervals.

For Finland, deaths are available from age zero onwards, starting with the year 1878. Lexis triangles were constructed by the team of the Human Mortality Database using the aggregate death counts published in various statistical publications by year of birth, year of death and age. This implies that the cohorts born before 1878 are included from the age they had reached in 1878 onwards. Thus, members of the cohort born in 1850 are in the database from age 28 onwards, while data are available from age zero onwards for members of the youngest cohort in this analysis, who were born in 1889. 
For Sweden, Lexis triangles of deaths are available from age zero onwards starting in 1751. However, the quality of the data improved tremendously after 1860, when the compilation of population and death counts based on all parish registers sent to Statistics Sweden began. Age reporting has been extremely accurate since 1861, but age exaggeration was a problem before that date.

Two major period effects modify the hazard rates in our analysis. For Finland, we include one variable to capture the effect of the declaration of independence from Russia in 1917, which resulted in a short civil war from January to May 1918, the same year that Finland was hit by the Spanish Flu Pandemic. The variable takes the value one for the year 1918, and zero otherwise. The second variable captures the two wars fought by Finland against the Soviet Union during the Second World War: the Winter War from November 1939 to March 1940, and the Continuation War from June 1941 to September 1944. Both period factors had a significant impact on Finnish mortality. The Spanish flu resulted in an estimated excess mortality of $33 \%{ }^{21}$, which is a comparatively low mortality increase compared to other European countries. During WWII remaining life expectancy at age 60 dropped for both sexes combined from 14.93 years in 1938 to a minimum of 14.19 years in 1940 (http://www.mortality.org). For Sweden, two period effects have been included in two separate variables: the Spanish Flu pandemic of 1918 with an estimated excess mortality of $78 \%{ }^{21}$ and World War II from 1939 to 1945. Because Sweden remained neutral during both world wars, they were minimally affected by the wars relative to other European countries. The WWII-period effects for Finland and Sweden differ by one year. Using similar period factors for both countries does have only minor effects on the results.

Cohorts lived through these period effects at various ages. The two oldest cohorts (1850-1854, 1855-1859) experienced the events of 1918 at ages 59-68, while in this analysis, the younger 
cohorts were not exposed because the events happened before their $60^{\text {th }}$ birthday, which is the starting age of our analysis. The oldest cohort was aged 85 to 94 (Finland)/95(Sweden) during WW II, and the second oldest was aged 80 to 89/90. Birth cohorts 1885 (Finland)/ 1886 (Sweden) and younger do not experience the period effect of WW II in this analysis, because at that time they were younger than age 60. All analyses were performed using STATA 11.

\section{RESULTS}

Table 1 shows the parameter estimates of the hazard models for Finland. Both the variance of the frailty distribution $\sigma^{2}$ and the age-independent level of mortality $a$ fluctuate considerably over the cohorts, and reveal countercyclical trends. We do not want to over-interpret the separate parameters of the model due to the fact that there is a trade off between $a$ and $\gamma$ and their effects on the mortality rate ${ }^{22}$. For females the cohorts 1866-1868 and 1869-1874 are characterized by significantly higher mortality levels $a$ and significantly smaller variances $\sigma^{2}$ as compared to the adjacent cohorts; the reverse is true for male cohorts 1860-1865 and 1866-1868, where $a$ is significantly lower and $\sigma^{2}$ significantly larger. Considering the age-independent parameter $\alpha$ as part of the frailty distribution results in a highly increased log cohort variance for the birth cohorts 1860-1865 and 1866-1868 among Finnish males. For the two cohorts combined the $\log$ cohort variance is significantly larger than for earlier birth cohorts $\left(\ln \left(\sigma^{2} \alpha^{2}\right)=-9.407 ; 95 \%\right.$ CI: -9.625 - -9.189). The log cohort variance is smallest for the 1869-1874 cohort, which is born immediately after the famine. Among Finnish females differences in the log cohort variance are much smaller than among males. For them, the birth cohort 1860-1865 reveals the highest log cohort variance, while the famine cohorts together with those born immediately after the famine have the smallest log cohort variance. For male birth cohorts 1860-1865 and 1866-1868 the log cohort variances differ significantly between Sweden and Finland, for females this is true for the birth cohorts 1855-1859 and 1860-1865 (Figure 1 and Figure 2). 


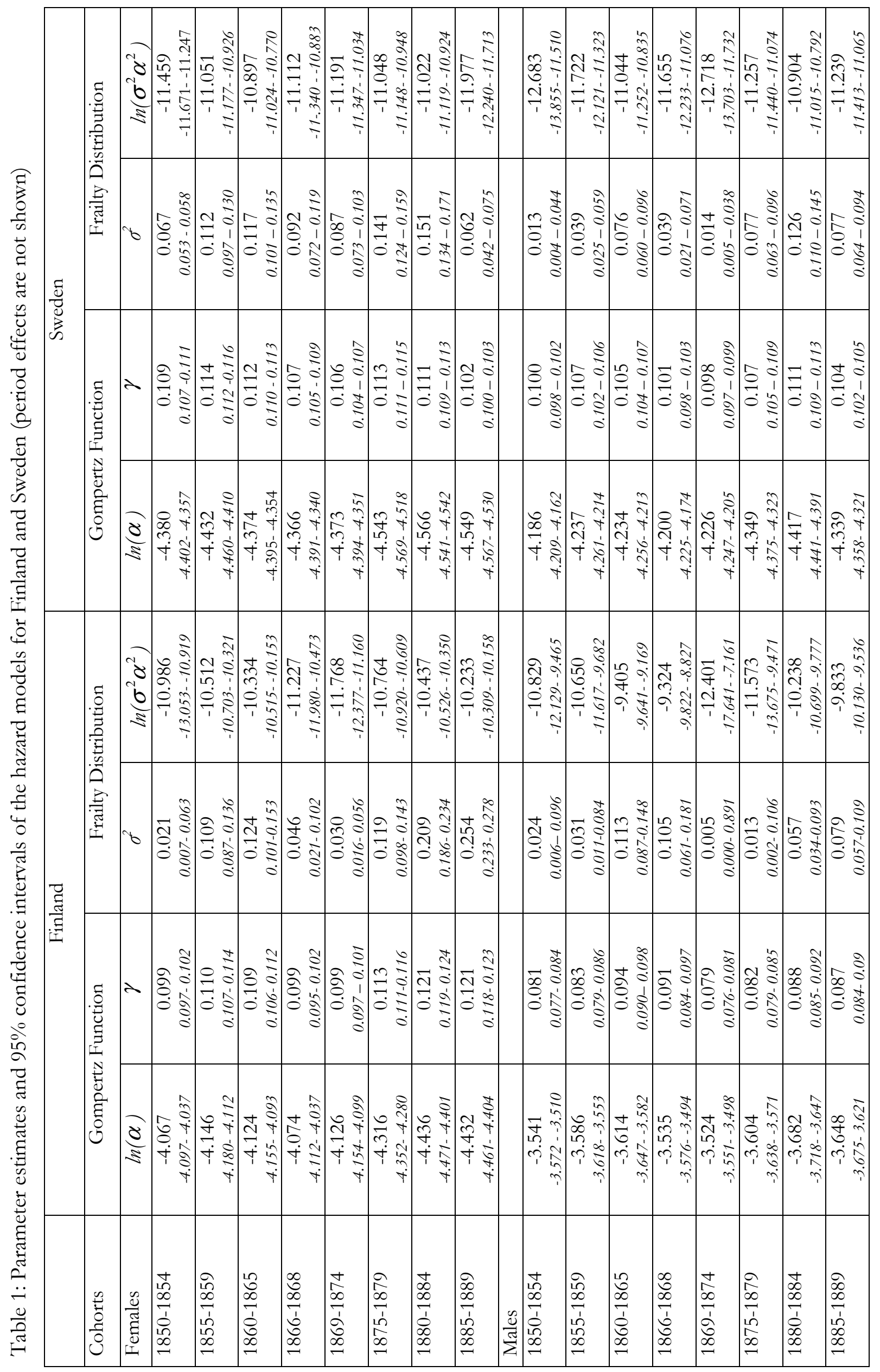


Figure 1: The $\log$ cohort variance $\ln \left(\sigma^{2} \alpha^{2}\right)$ and $95 \%$ confidence intervals of female cohorts born 1850 to 1889 for Finland and Sweden

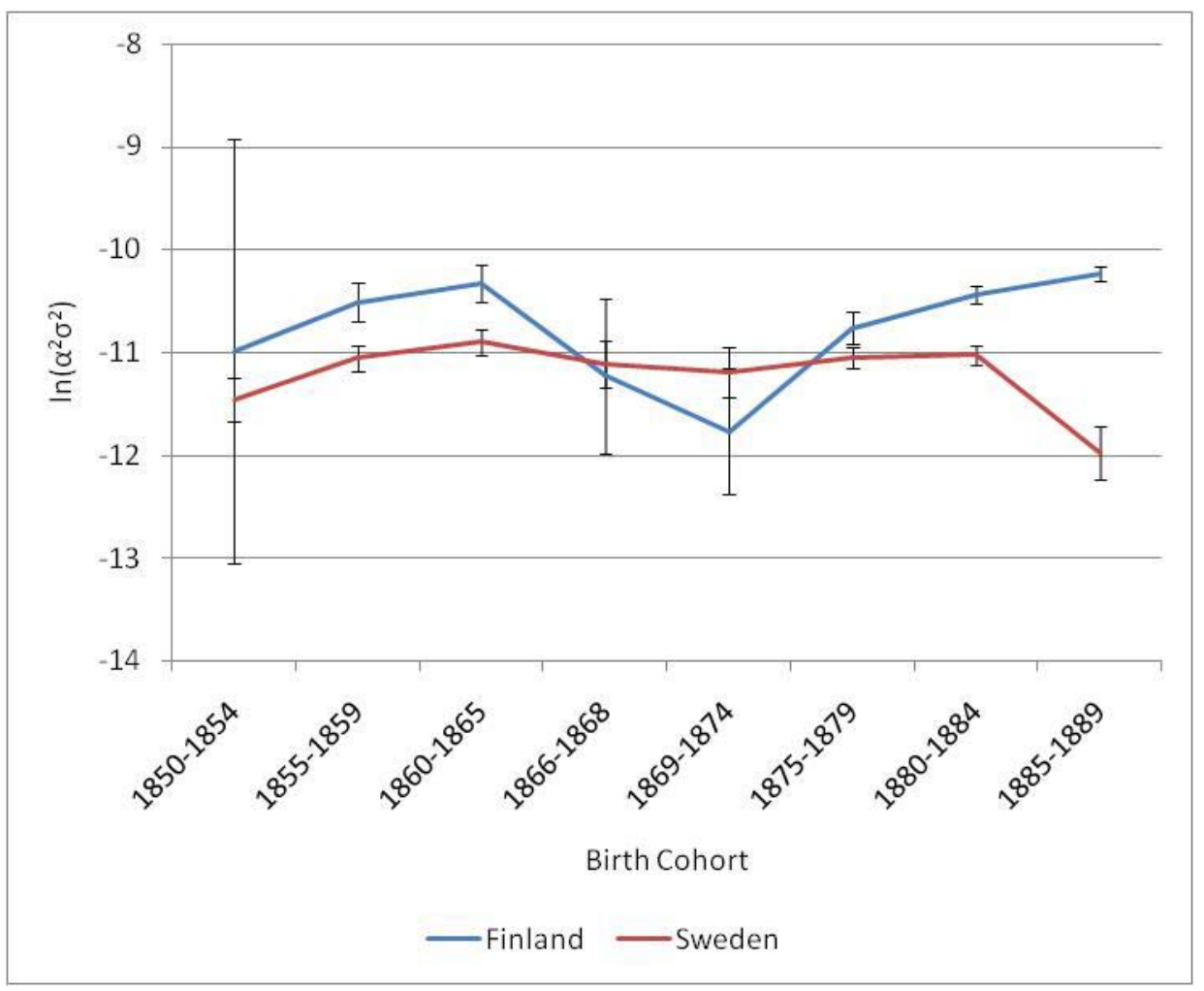

Figure 2: The log cohort variance $\ln \left(\sigma^{2} \alpha^{2}\right)$ and $95 \%$ confidence intervals of male cohorts born 1850 -1889 for Finland and Sweden

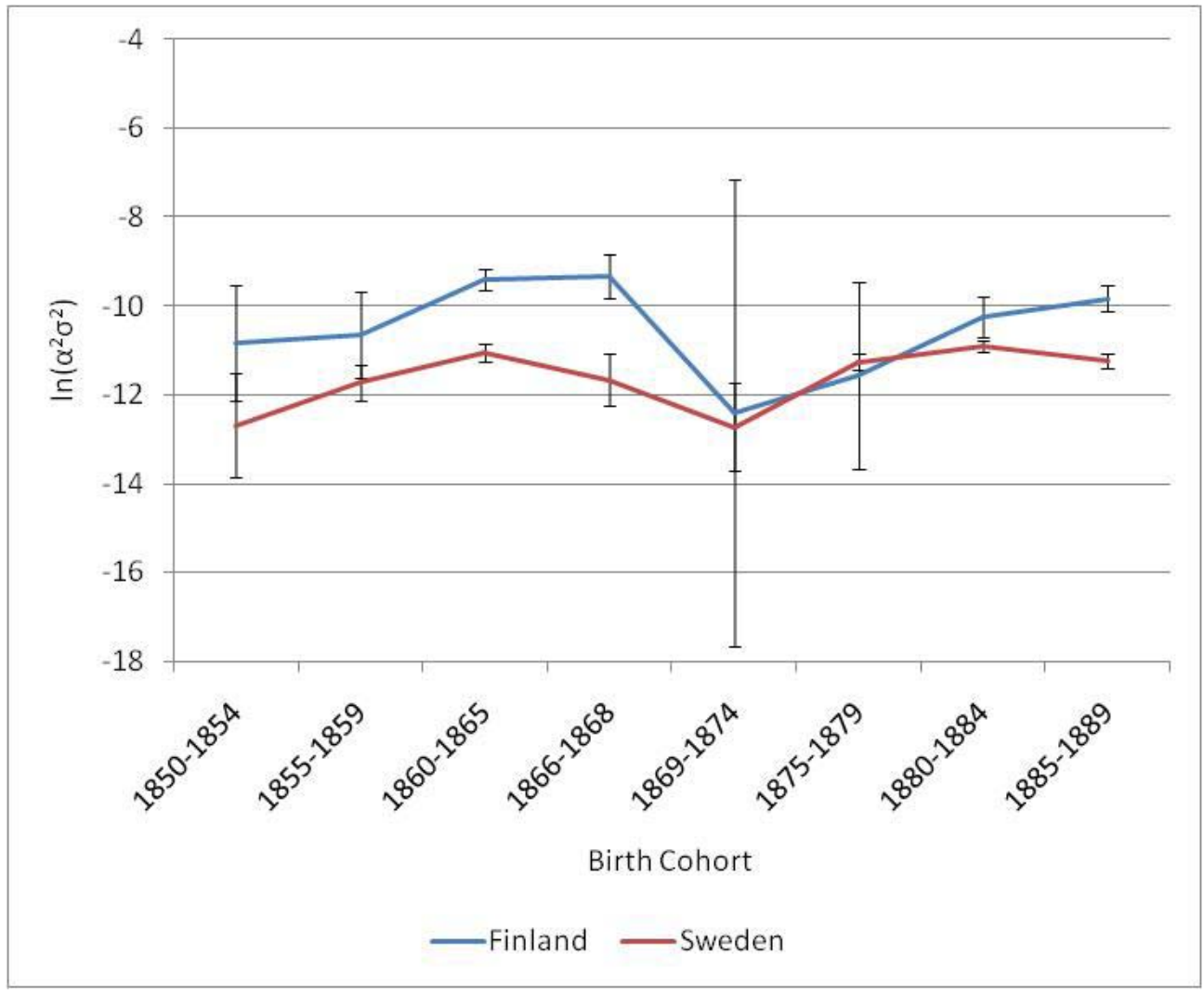


Figures 3 and 4 show the estimated frailty distributions (Equ. VI) of the three adjacent Finnish birth cohorts 1860-1865, 1866-1868, and 1869-1874. For both sexes the pattern is similar for the pre- and post-famine cohorts: the 1860-1865 cohort combines a low frailty level with a large cohort variance. On the contrary, the 1869-1874 cohort has a high level of frailty together with a small cohort variance. The frailty distributions of the famine cohorts differ between the sexes: for males, a low frailty level is combined with a large variance, thus, resulting in a distribution similar to that of the 1860-1865 cohort. For females, the frailty distribution is similar to that of the postfamine cohort 1869-1874. The frailty distributions of Swedish cohorts are remarkably stable and show little variations in terms of their means and variances with the only exception of the 18691874 male cohort, which has a comparatively small variance.

Figure 3: Frailty distribution of female cohorts born 1860-1865, 1866-1868, and 1869-1874 in Finland and in Sweden

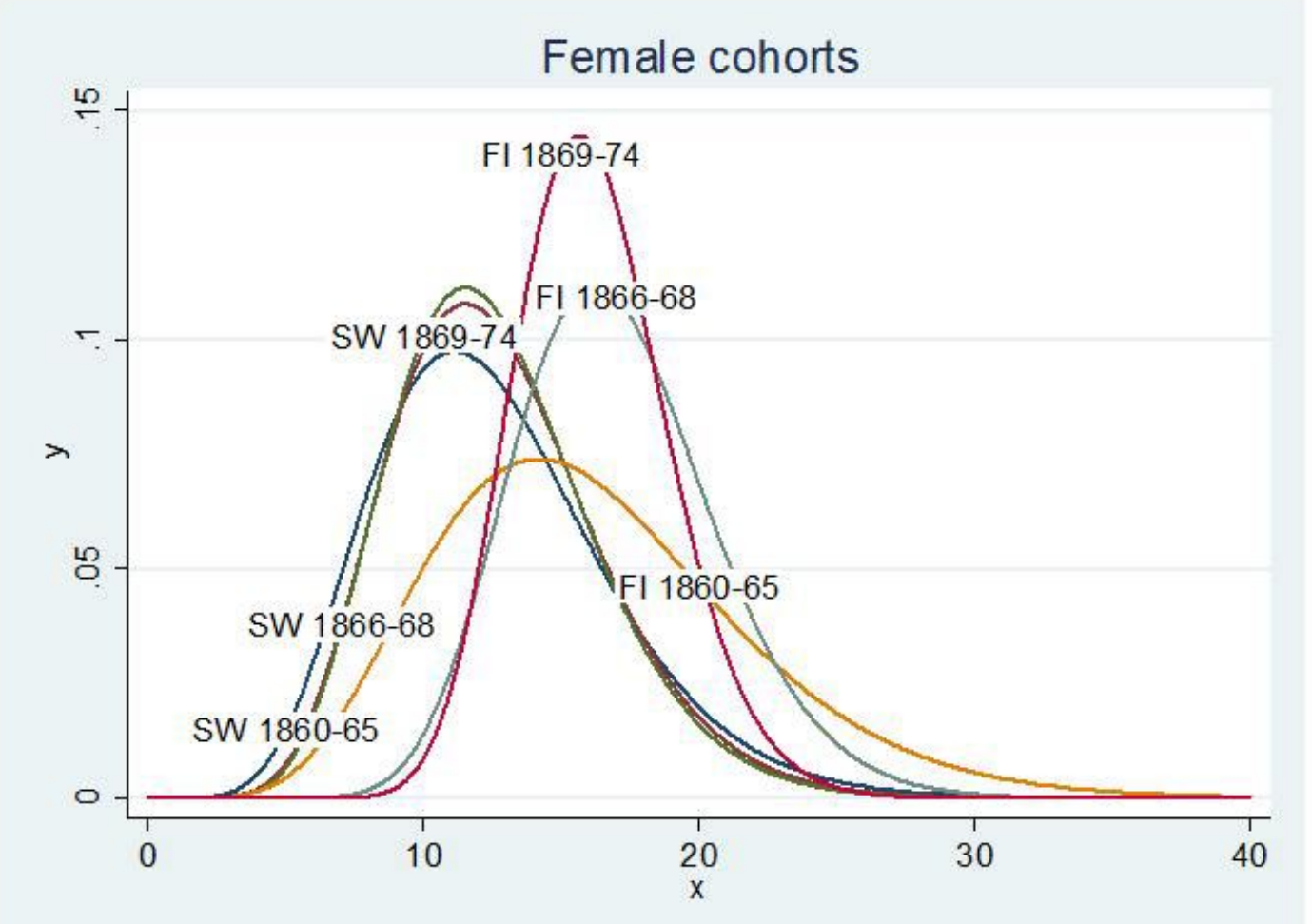


Figure 4: Frailty distribution of male cohorts born 1860-1865, 1866-1868, and 1869-1874 in Finland

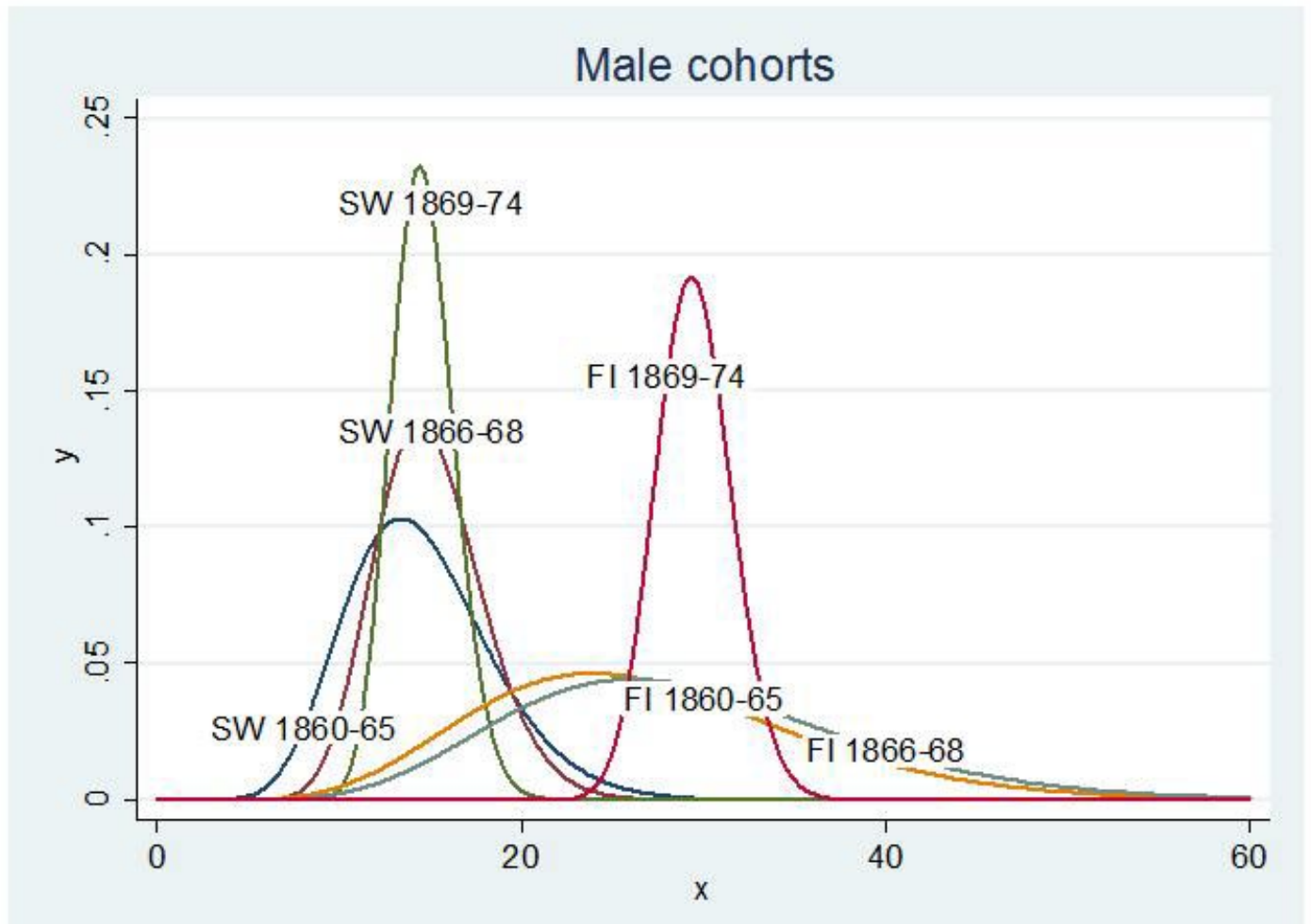

Figures 5 and 6 compare the standardized life expectancy between Finland and Sweden. For males, it is lowest for the birth cohorts 1866 to 1868 , and it is second-lowest for the cohorts 1860 to 1865 . The difference between the cohort born immediately after the famine (1869-1874) and the famine-cohort is 0.83 years, and 0.53 years for cohorts born 1860-1865. Among Finnish females, standardized life expectancy is lowest for the cohorts born before the famine (18601865). The difference from the cohorts born immediately after the famine is 0.89 years, while the difference between the famine-cohort and those born after the famine is 0.37 years. Sweden does not show any large disturbances in standardized life expectancy for these cohorts. 
Figure 5: Standardized life expectancy at age 60 for female cohorts born 1850 to 1889 in Finland and Sweden

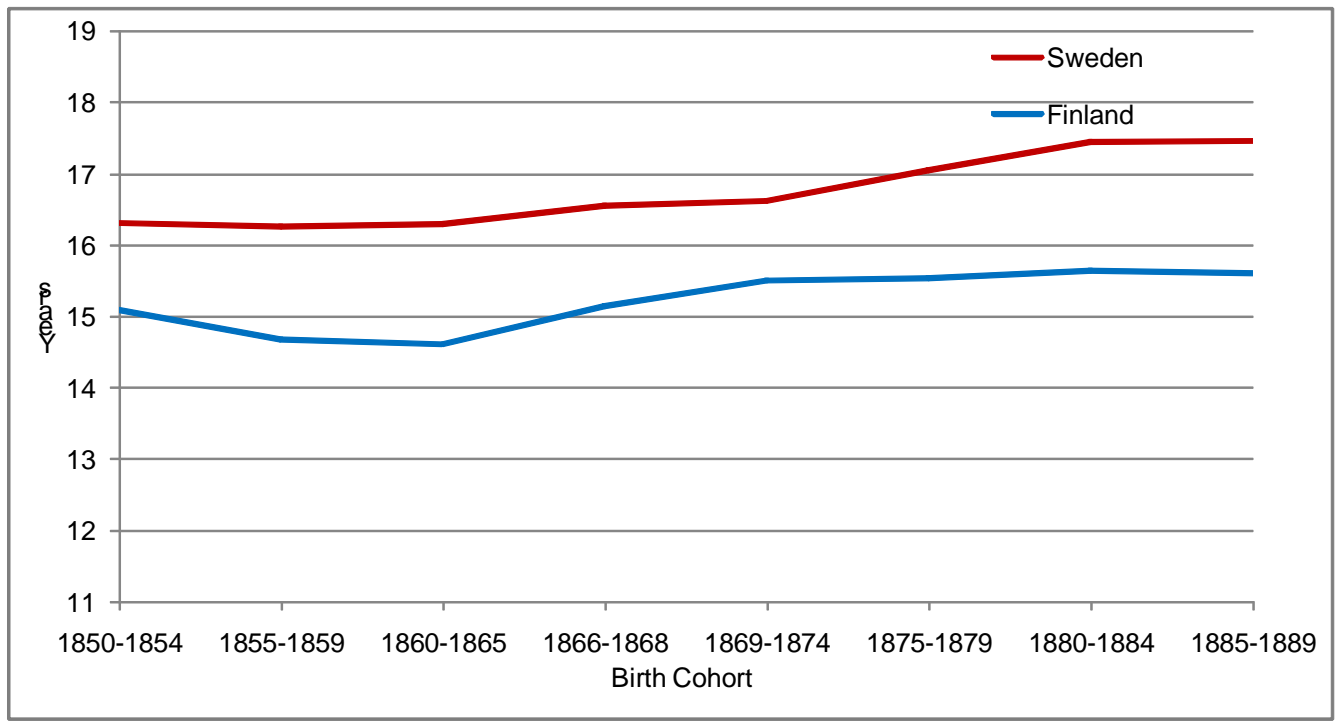

Figure 6: Standardized life expectancy at age 60 for male cohorts born 1850 to 1889 in Finland and Sweden

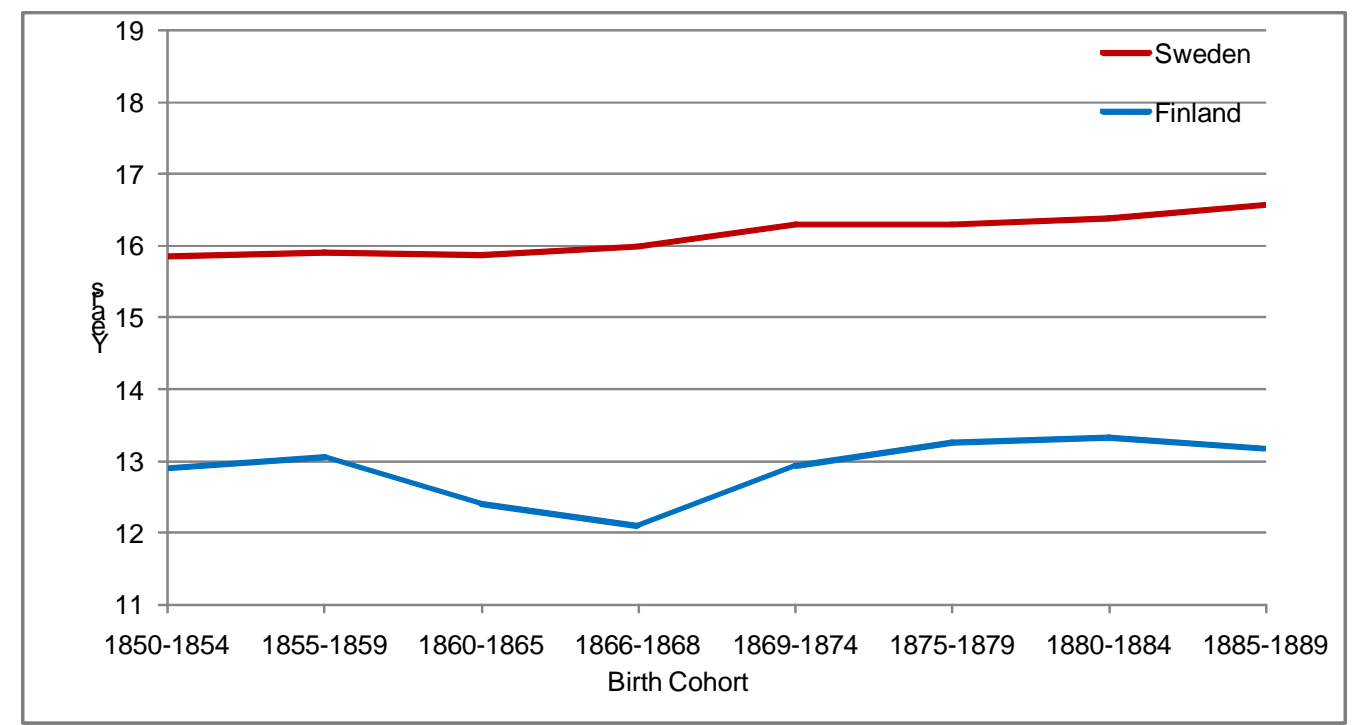




\section{DISCUSSION}

Selection forces of fertility and mortality alter the frailty distributions of cohorts. We show that cohorts born in Finland born immediately before the Great Finnish Famine (1860-1865) are highly heterogeneous in their distribution of deaths after age 60. Also male cohorts born during the Great Finnish Famine (1866-1868) show increased heterogeneity. By contrast, those born in the years immediately after the famine (1869-1874) seem to be particularly homogeneous.

Taking changes in the frailty distribution into account results in lower standardized life expectancy of about one year for male cohorts born during the Great Finnish Famine. The cohorts born immediately before the famine display the second-lowest standardized life expectancy. The absence of any effect among male Swedish cohorts born during the period of the Finnish famine further supports the assumption that the famine in Finland had long-term negative effects.

For females, the results are less clear. As mentioned above, heterogeneity in the age at death is largest for the pre-famine-cohorts. The cohorts born between 1855 and 1865 experience the lowest life expectancy losing about one year of life relative to the cohorts born immediately after the famine. Those born during the famine are only marginally affected

In the Finnish cohort data, most of the mortality takes place in the age interval 60 to 80 . For this age interval, Kannisto and colleagues merely look at one particular outcome measure, namely the survival probability that one reaches the age of 80 conditional on having reached the age of 60 . They estimate this non-parametrically as a single number, separately for men and women and separately for each birth cohort. They find that this probability does not vary across birth cohorts. This is not inconsistent with our paper. We estimate mortality rate models that exploit the timing 
of mortality beyond age 60 , and this enables us to identify and estimate richer models. We have three parameters to explain the data patterns between 60 and 80: $\alpha, \sigma^{2}$, and $\gamma$. Different combinations of values for the three parameters may lead to the same aggregate survival probability between 60 and 80 . Note that if our parameter $\alpha$ changes then the mean frailty among those aged 60 changes. So the mean frailty among those aged 60 may change over cohorts even though the aggregate survival probability between 60 and 80 does not change (provided that $\sigma^{2}$ or $\gamma$ changes as well). The mitigating effects of mean and variance on aggregate survival probabilities are a key aspect of our paper.

We do not apply the widely used Cox-proportional-hazard models because we explicitly want to model the age-specific force of mortality and estimate its parameters. The hazard model used in our study assumes that mortality beyond age 60 follows a Gompertz-function, which is the appropriate functional form for historical mortality patterns.

A noteworthy finding of this study is that both the standardized life expectancy of those born during the famine (males) and of those born before the famine (both sexes) was reduced. There may be two reasons for this phenomenon: (1) the definition of the time period of the Great Finnish Famine may be too narrow, and (2) the repeated outbreak of childhood diseases before the famine may have had negative long-term effects on the health of the respective cohorts. When defining famine, taking only harvest patterns into account is certainly insufficient. Famine is characterized by a considerable shortfall in food intake by a sizable number of people, and often is rooted in a preceding crop failure. However, many authors emphasize that the social disruption and economic chaos caused by a famine ${ }^{15,23,24}$ is as important-and is sometimes even more important - than the food shortages themselves ${ }^{23,24}$. Large-scale migration; the separation and uprooting of families; an increase in crime; the loss of land, livestock and other assets of production; mental disorientation; the consumption of alternative subsistence foods and loss of 
body weight are all factors that contributed to the large numbers of excess deaths. Thus, the core period of a famine is often defined by death counts.

In the 1860 s, the first year with a peak in the total number of deaths was 1863 . In this year, excess deaths were mainly the result of childhood diseases, such as measles and whooping cough. Death counts from these two causes of death were twice as high in 1863 as they were during the actual famine years ${ }^{15}$. Mortality started to increase again, in spring 1866, and reached a second peak in spring 1867. After a rapid increase from December 1867 onwards, mortality reached catastrophic levels between March and August 1868. Despite a decrease in mortality from September 1868 onwards, mortality remained at high levels until summer 1869.

Based on harvest patterns and death counts, it is possible to argue that the cohorts born from the beginning of the 1860 s until the end of 1868 were repeatedly exposed to hazardous circumstances early in life: crop failures since 1862, the epidemic of childhood disease in 1863, as well as the Great Famine between 1866 and 1868. Many of these years were characterized by high levels of infant mortality and childhood disease. In terms of infant and child mortality, the year 1863 stands out; a fact that was already noted by Pitkänen ${ }^{15}$ when he compared mortality during the famine with pre-famine years. He pointed out that, when the pre-famine years, including the year 1863, are used as a basis for studying the infant and child mortality of the famine years, the impact of the famine may be underestimated

This is not the only study that finds that the long-term effects of early life circumstances differ by gender, and that the results for women are less conclusive than for men. For example, the effect of the business cycle at birth on late life mortality is stronger for men than for women in the Danish twin data ${ }^{3}$, and in Dutch data ${ }^{25}$. This is also true for the effect of the Dutch Potato Famine on late-life mortality ${ }^{10}$. A medical study on the relation between birth weight and 
mortality from heart disease finds stronger effects for $\operatorname{men}^{26}$. Men with certain health problems that might originate earlier in life are more likely to die than women with the same conditions ${ }^{27}$. Pitkäinen found large sex differences in the Finnish famine mortality figures, with males being far more likely than females to die. Although this sex differential is particularly large for ages 10 to 40 in the high-impact areas of the famine, it also exists for younger ages ${ }^{15}$. It has been hypothesized ${ }^{28}$ that the smaller impact for females may be explained by a so-called male vulnerability because males are the heterogametic sex: they have an unprotected Y chromosome and, therefore, they may be more vulnerable to adverse environmental conditions in the short as well as in the long term.

This study has two major limitations. First, because cohort data based on Lexis triangles only exist on a yearly basis, the critical periods during pregnancy or the first years of life cannot be exactly defined. In order to identify the impact of the period effect on the variance of the frailty distribution, we had to combine several birth cohorts that lived through these events at various ages. It is important to note that we find a long-term detrimental effect of being born during the famine although the date of birth classification is not very specific with respect to the timing of the exposure in defined critical periods around birth.

Second, since the data apply to the whole country, no regional variation in the timing and the severity of the famine can be explored. On the other hand, this limitation also lends strength to this study. Selection effects due to migration out of the study area, a problem usually encountered in historical studies based on parish data, do not play a role.

In conclusion, the long-term negative effects of famine on adult health and mortality may be hidden by mortality and fertility selection, and may only be seen after accounting for differences in the frailty distributions of the cohorts. In the context of the historical famine in Finland, the 
negative long-term consequences on mortality may be attributable to childhood disease and to typhus/dysentery, rather than to starvation. 


\section{References:}

1 Bengtsson T, Lindström M. Airborne infectious diseases during infancy and mortality in later life in southern Sweden, 1766-1894. Int Journal of Epidemiol 2003; 32:286-294

2 Fridlizius G. The deformation of cohorts: nineteenth century mortality in a generational perspective. Scandinavian Economic History Review 1989; 37:3-17

3 van den Berg G, Doblhammer G, Christensen K. Exogenous determinants of early-life conditions, and mortality later in life. Social Science \& Medicine 2009; 68: 1591-1598

4 Doblhammer G, Vaupel JW. Life span depends on month of birth. Proc Natl Acad Sci 2001; 98:2934-39.

5 Doblhammer G. The late life legacy of very early life. Berlin: Springer, 2004

6 Barker DJP. Mothers, Babies, and Disease in Later Life. London: British Medical Journal Publishing Group, 1994

$7 \quad$ Hales CN, Barker DJ. The thrifty phenotype hypothesis. Br Med Bull 2001;60: 5-20.

8 Leon AD. Biological theories, evidence, and epidemiology. Int J Epidemiol 2004; 33:1167_ 1171

9 Lumey L.H. , Stein A.D., Susser E.. Prenatal Famine and Adult Health. Annu. Rev. Public Health 2011. 32:24.1-24.26. doi:10.1146/annurev-publhealth-031210-101230

10 van den Berg G, Lindeboom M, Portrait F. Long-run Effects on Longevity of a Nutritional Shock Early in Life: The Dutch Potato Famine of 1846-1847. IZA working paper 2007 ;

11 Kannisto V, Christensen K, Vaupel JW. No Increased Mortality in Later Life for Cohorts Born during Famine. Am J Epidemiol 1997;145: 987 - 994

12 Painter RC, Roseboom TJ, Bossuyt PMM, Osmond C, Barker DJP, Bleker OP. Adult mortality at age 57 after prenatal exposure to the Dutch famine. European Journal of Epidemiology 2005; 20: 673-676

13 Shige S. Does famine have a long-term effect on cohort mortality? Evidence from the 1959-1961 great leap forward famine in China. J. Biosoc. Sci. 2009; 41: 469-491

14 Stein ZA, Susser M, Saenger G, Marolla F. Famine and Human Development: The Dutch Hunger Winter of 1944-1945. New York: Oxford University Press, 1975

15 Pitkänen KJ. Mortality during the Great Finnish Famine of the 1860s. Finnish Demographic Society: Helsinki, 1993

16 Vaupel JW, Manton KG and Stallard E. The impact of heterogeneity in individual frailty on the dynamics of mortality. Demography 1979; 16: 439-454

17 Christensen K, Doblhammer G, Rau R, Vaupel JW. Ageing populations: the challenges ahead. The Lancet 2009; 374:1196-1208 
19 Van den Berg GJ. Duration models: specification, identification and multiple durations. (eds) JJ Heckman and E Leamer, Handbook of Econometrics 2001; 5(55):3381-3463. NorthHolland, Amsterdam.

20 Wilmoth JR, Andreev K, Jdanov D, et al. Methods Protocol for the Human Mortality Database, http://www.mortality.org/hmd/SWE/InputDB/MethodsProtocol.pdf, 2007

21 Ansart, S., Pelat, C., Boelle, P.-Y., Carrat, F., Flahault, A. and Valleron, A.-J. Mortality burden of the 1918-1919 influenza pandemic in Europe. Influenza and Other Respiratory Viruses 2009, 3: 99-106. doi: 10.1111/j.1750-2659.2009.00080.x

22 Thatcher AR. The long-term pattern of adult morality and the highest attained age. J.R. Statist. Soc. A 1999; 162(1):5-43

23 Ó Gráda C. Making Famine History, J Econ Lit 2007; XLV, 5-38

24 Ó Gráda C. Famine Demography, Working paper series UCD Centre for Economic Research 2007: WP07/21

25 Van den Berg, G.J., M. Lindeboom and F. Portrait. Economic Conditions Early in Life and Individual Mortality. American Economic Review 2007; 96, 290-302

26 Leon, D.A., Lithell H.O., Vågerö, D., Koupilová,I., Mohsen, R., Berglund, L., Lithell,UB., McKeigue, P.M. Reduced fetal growth rate and increased risk of death from ischaemic heart disease: cohort study of 15000 Swedish men and women born 1915-29. BMJ 1998; 317, 245-252.

27 Case A., Paxson, C. Sex differences in morbidity and mortality. Demography 2005;42 (2), $189-214$

28 Low, BS. Why sex matters: A Darwinian look at human behavior, Princeton NJ:

Princeton University Press. 